\title{
Teaching to the Other Side of Campus: An Engineering Professor's Experi- ence with an Honors College Course
}

\section{Dr. John R. Reisel, University of Wisconsin, Milwaukee}

Dr. John R. Reisel is a Professor of Mechanical Engineering at the University of Wisconsin-Milwaukee (UWM). His research efforts focus on engineering education, combustion and energy utilization. Dr. Reisel was a 2005 recipient of the UWM Distinguished Undergraduate Teaching Award, a 2000 recipient of the UWM College of Engineering and Applied Science Outstanding Teaching Award, and a 1998 recipient of the SAE Ralph R. Teetor Educational Award. Dr. Reisel received his B.M.E. degree from Villanova University in 1989, his M.S. degree in mechanical engineering from Purdue University in 1991, and his Ph.D. in mechanical engineering from Purdue University in 1994. 


\title{
Teaching to the Other Side of Campus: An Engineering Professor's Experience with an Honors College Course
}

\begin{abstract}
There is a great need in the United States to increase the overall technical literacy of the population. To help meet this need, engineering courses are being taught in grade schools and high schools across the country; such courses are increasing the interest of students to pursue engineering degrees in college and are teaching some of the thought processes used by engineers to the students. At the university level, there are the occasional engineering courses offered to non-engineering majors, but such courses are frequently low-level and often not taught by regular faculty. As such, students taking such courses may only receive a brief overview of the engineering discipline.
\end{abstract}

Some have argued that engineering faculty need to do more to increase the technical literacy of a broad-spectrum of students. But putting non-majors in the mid-level or upper-level engineering courses often taught by faculty would result in overwhelmed students attempting to learn engineering course material without prerequisite knowledge; such an approach is likely to do more harm than good. An alternative approach is to develop courses for upper-level nonengineering students based on technical subjects that (a) are interesting and educational to the students, (b) do not rely on large amounts of prerequisite knowledge and mathematical skills, and (c) are taught by regular engineering faculty. Such courses can then be offered as elective courses to students in non-engineering disciplines. These courses would offer students in other disciplines the opportunity to learn about technical subjects of current importance from engineers with expertise in these areas, but without expecting mathematical rigor for which they may not be prepared.

In this paper, the author describes his experiences with preparing and teaching a seminar course to non-engineering students offered through the Honors College at the University of WisconsinMilwaukee. The course was a general course about energy, and covered issues involving energy associated with transportation, electricity generation, and building systems. The paper discusses finding the appropriate level of coverage of the subject material, the challenges and opportunities with teaching in a seminar-style format, and setting appropriate expectations for upper-level students from a variety of non-engineering disciplines. The paper also includes lessons learned from the course so as to improve the course in future offerings.

\section{Introduction}

In recent years, there has been recognition that increasing the technological literacy of the general populace is important. Krupczak, et al., discuss how the general populace needs to understand technology, including its creation and its impact on society. They also differentiate between technological literacy and engineering literacy. The American Association for the Advancement of Science, and the National Academy of Engineering have weighed in on the importance of everyone being literate with respect to technology and the role of engineering in 
society. ${ }^{2,3}$ Klein and Balmer ${ }^{4}$ summarize some of the reasons for increasing technological literacy, particularly among students majoring in the liberal arts. In the preface to its technological literacy standards, the International Technology Education Association points out that while society is increasingly driven by technology, many people do not understand how various elements of technology work or is developed - as a result, most people do not participate in making decisions that affect the technology that they depend upon. ${ }^{5}$ This can leave people vulnerable to abuse by those who understand technology and how to make it work primarily in their favor. Improved technological literacy provide people with a defense against such potential abuse by enabling people to make well-informed decisions about technology on a personal level as well as through nationwide choices as determined by the people in a democratic society. ${ }^{6}$ As people who teach the application of scientific knowledge to solving problems, engineering faculty can play a valuable role in improving technological literacy for a wide audience by teaching courses on engineering topics to non-engineering majors.

Such courses for non-engineering majors can take various forms. ${ }^{7-9}$ Courses can take the form of a traditional lecture, with the engineering professor lecturing on technical subjects to a large group of non-majors. While such a course has the advantage of exposing a large number of students to some science and engineering knowledge, unless well-done, such a course is likely to have minimal impact on the overall understanding of technological or engineering principles and practices for most of the students. Courses could also be centered on laboratory experiments, which allow the students to gain hands-on experience with engineering principles. The Mechanical Engineering Department at the University of Wisconsin-Milwaukee (UWM) has such a course, and it provides the students who are able to take it with a fairly solid understanding of simple engineering concepts. While this may provide some appreciation of engineering to the non-majors in the course, it likely does not deeply influence their thinking about engineering concepts years later. In addition, these types of courses can be severely limited in size due to the resources needed for conducting a laboratory-based course.

A third format is that of a seminar format, which consists of a small number of students actively engaged in dialogue about engineering-related topics. The seminar format is the subject of this paper. The author developed and taught a seminar course on energy for students in the Honors College at UWM. It should be noted that this is a format that many engineering instructors are not particularly familiar or comfortable with, and teaching to non-engineering majors is also an area where engineering faculty may not be experienced. In order to assist other engineering faculty who may be contemplating teaching such a course, this paper contains a description of the course, and strategies on how to develop the course format and promote student participation. In addition, a discussion of some of the benefits that teaching such a course offers engineering faculty members is provided in order to encourage more engineering faculty to undertake such a task, thereby further increasing the technological literacy of non-engineering students.

\section{Course Description}

The Honors College at UWM consists of high-achieving students and is open to students from all disciplines. (While many engineering students are academically qualified for the Honors College, there are relatively few engineering students who complete studies in the Honors College due to the difficulty in fulfilling the curricular requirements of the Honors College on 
top of the engineering program requirements in a timely manner.) As part of their studies, Honors College students need to take several upper-level Honors Seminars courses, which are taught by faculty from many disciplines at UWM. The course described in this paper was an upper-level Honors Seminar in the Natural Sciences entitled "Energy: Sources, Uses and Economics". This course also served as one of the required Natural Sciences courses to satisfy the university's General Education Requirements. As such, students who are not majoring in engineering or the natural sciences will tend to gravitate to such a course.

The course was limited in size to 15 students, and was filled to capacity. The students in the course had a variety of primary majors in non-STEM fields, including students from business, education, humanities, fine arts, and social science majors. Befitting an upper-level seminar course, 14 of the 15 students had junior or senior standing, with the remaining student holding sophomore standing. There were no prerequisites for the course, other than sophomore standing and the requirement of having taken a lower-level Honors Seminar course.

The formal objectives of the course were as follows.

(1) Students will learn the fundamentals of the sources and uses of energy in the world today.

(2) Students will understand the energy limitations facing the world.

(3) Students will learn the basic economic influences on energy.

(4) Students will understand the environmental impacts and implications of the world's energy consumption.

Essentially, the instructor's goals for the course were to introduce non-engineering students to the realities of energy consumption in the world today, how electricity is produced, how transportation energy needs are met, how heating is provided to processes and facilities, how energy choices are often driven by economics, and how energy choices impact the environment. Furthermore, consideration of the future of energy was brought into the course. Understanding these items is important for increasing the technological literacy of non-STEM students by focusing on a topic that is important for all, and therefore can be seen as relevant by all. Finally, a goal of the course was to provide these non-engineering students with insights as to how engineers will view a problem and how engineers will proceed in finding solutions to problems.

Referencing back to the distinctions between technological literacy and engineering literacy developed by Krupczak et al. ${ }^{1}$, it can be considered that this course sought to improve both literacies of the students in the class. The topical coverage of the technologies that use and produce the various sources of energy enhances the level of technological literacy of the students. The coverage of the environmental effects and economics of the different energy sources help relate the technology to the rest of society, further deepening technological literacy. The students are also asked to view their particular energy use through the eyes of an engineer, and approach the problem of reducing their energy consumption as an engineer would; this provides the students with insights into the process of engineering and increases their engineering literacy.

While the ITEEA Standards for Technological Literacy ${ }^{5}$ are strictly designed for K-12 students, this course does connect well with their standards on The Nature of Technology and an 
understanding of Technology and Society. Much of the course is focused on understanding the different energy sources and the use of energy from those sources, and on the environmental and economic impacts of the energy sources. Therefore, this course either helps reinforce the K-12 standards at a college level, or helps to fill in the gaps in the education of these students on their understanding of these topics. Also, by giving the students some experience with doing engineering work, and through the preliminary discussions of how engineers would go about solving a problem, the course sought to provide students with a better understanding of engineering and the engineering profession, thus helping to address the concerns discussed by the NAE. ${ }^{3}$

The course was designed around weekly topics. These topics are listed in Table 1.

The class met twice a week, for 75 minutes on both Monday and Wednesday. Typically, after finishing up the discussion on the previous week's topic, the instructor spent approximately 30 minutes of the Monday class introducing some of the science, technology and economics behind the weekly topic. In doing so, recognizing the background of the students in the course, the instructor relied more of descriptive portrayals of the technology, and less on the equations that would be routinely used in engineering courses. However, simple equations were used throughout the course, but were always reinforced verbally with the concepts represented in the equations. The derivation of equations was avoided. After introducing the fundamentals of the topic, the instructor would usually open up a class discussion on the topic with some fundamental questions. Students were expected to have read background material on the topic from the textbook and other sources before class. At the end of the class, the instructor would leave the students with two or three questions that they were to research for the next class on that topic. The Wednesday class typically centered around class discussion of those questions. Depending on the weekly topic, additional material on the topic was often introduced by the

Table 1: Weekly Outline of Topics Covered in Energy Course

\begin{tabular}{|c|l|}
\hline Week & \multicolumn{1}{|c|}{ Topic } \\
\hline 1 & Introduction: What is Energy? \\
\hline 2 & Fundamentals of Energy Systems (electricity, transportation, heating) \\
\hline 3 & General Overview of Energy Use Trends \\
\hline 4 & Fossil Fuels - Coal \\
\hline 5 & Fossil Fuels - Petroleum \\
\hline 6 & Fossil Fuels - Natural Gas \\
\hline 7 & $\mathrm{CO}_{2}$ and Climate Change \\
\hline 8 & Nuclear Energy \\
\hline 10 & Hydroelectric Power \\
\hline 11 & Geothermal Power \\
\hline 12 & Solar and Wind Power \\
\hline 13 & Oceanic Power \\
\hline 14 & Biofuels \\
\hline 15 & Energy Conservation \\
\hline
\end{tabular}


instructor during the Wednesday class. For example, during the week on petroleum, the Monday class session had technical information presented by the instructor on what petroleum is, where it comes from, how it is recovered, processed, and distributed, and a discussion on how internalcombustion engines work. In the Wednesday class session, information was provided on the availability of petroleum, what happens chemically during combustion (to describe where the $\mathrm{CO}_{2}$ comes from), and the future of petroleum. At the end of the Wednesday class in the week, students would be left to research either additional questions on that topic, or questions to lead off a discussion of the next week's topic. If it was the former, the next week would start by finishing up discussion on the previous topic, and if it was the latter, the next week would start with a technical introduction to the new topic, followed by class discussion of the questions on the new topic.

During the semester, each student was required to be a discussion leader once. As discussion leader, the student would introduce the questions to be answered, and start the discussion on what they had learned. They would try to make sure the discussions stayed to the point, encourage participation by all students, and at the end prepare a summary of the class discussion on the topic. During this time, the instructor would add information if students were confused or incorrect in their information, but otherwise would leave the discussion to the students.

To satisfy the course requirements, the students needed to write three short mid-term papers (approximately 5 pages in length, and citing at least three references) and one final paper (approximately 10 pages in length). Students were given suggestions for the mid-term and final papers; these suggestions are listed in Table 2. Students were also encouraged to suggest other ideas for their papers, particularly with respect to their final paper. If students were able to identify a topic for their final paper that overlapped with their primary major, they were encouraged to explore that topic. For example, one student from education prepared as their final paper a lesson plan for $4^{\text {th }}$-grade students on energy. Another student from business did a case study on the Enron case to explore how energy economics could undermine a business.

From Table 2, it can be noted that one topic was required of all students - that of finding ways to save energy (and reduce their carbon footprint) at home. This was the avenue used to give the

Table 2: Suggested Topics for Mid-Term and Final Papers

\begin{tabular}{|c|l|}
\hline Type of Paper & \multicolumn{1}{|c|}{ Topic } \\
\hline Mid-Term & Fracking, pros and cons \\
\hline Mid-Term & Impact of gas prices on economy, political decisions \\
\hline Mid-Term & Coal recovery mining issues - impacts on environment and people \\
\hline Mid-Term & Wind energy pros and cons \\
\hline $\begin{array}{c}\text { Mid-Term or Final } \\
\text { (Required) }\end{array}$ & Ways to save energy at home/reduce carbon footprint \\
\hline Final & Stabilizing $\mathrm{CO}_{2}$ levels in the atmosphere - playing the wedge game \\
\hline Final & Achieving US Energy Independence - how to do it? Is it good? \\
\hline Final & Developing a transportation plan with reduced petroleum consumption \\
\hline
\end{tabular}


students an experience of how engineers may approach such a problem. They were to explore how they currently use energy, and identify ways of reducing their energy usage. They were expected to perform research on how much energy could be saved with changes in equipment or behavior modification, and then write this information as a plan to be implemented. They were to include estimates on how much energy would be saved and how much $\mathrm{CO}_{2}$ emissions would be eliminated. In this way, students were performing activities, albeit at a simpler level, similar to what engineering students in 20+ universities may do in an Industrial Assessment Center audit. $^{10}$

One of the options suggested for the final paper was to take the game of Stabilization Wedges from Princeton Environmental Institute at Princeton University, ${ }^{11}$ and propose a set of strategies to stabilize $\mathrm{CO}_{2}$ emissions. This concept was introduced in class, and the class had a discussion on which strategies they thought might be best to combine. Students who chose this as their final paper needed to explore the possibilities in greater depth, and justify their choices.

Twice during the class, the students conducted their discussions in a "debate" format. The class session before the debate, the students were divided into teams, and were given a topic to defend. The first debate was on fossil fuels, with the three teams being assigned to advocate for either coal, petroleum, or natural gas. The teams them presented the reasons for using that fuel, and reasons against the other fuels during the debate. The second debate surrounded around using ethanol as a vehicle fuel, with the teams advocating for expanding its use, reducing its use, or maintaining its use as is. These debates led to more lively discussions of the topics, as the student teams tried to "win" the debate in these friendly competitions.

One other class strategy that was employed at the end of the semester, after a discussion of energy conservation, was to walk the class around the building and have the students identify ways that energy consumption in and around the classroom building could be reduced. This again helped illustrate to the students some of what engineers do, and also drove home the idea that energy use is all around us, as are opportunities for more efficient use of energy.

The class grades were based upon the mid-term papers (each worth $15 \%$ of the course grade), the final paper (worth $30 \%$ of the course grade), and class participation (worth $25 \%$ of the course grade). As will be described later, this grading scheme provided challenges for instructor who was accustomed to relying on numerical test and homework grades to derive semester grades.

\section{Course Challenges and Strategies}

As described above, this course is significantly different from a traditional lecture-based or laboratory-based course for engineering students that most engineering faculty are comfortable with teaching. Several of these challenges are described below, and suggestions are provided for strategies that can be used by engineering faculty attempting to teach this type of seminar course.

\section{Level of the Material to be Taught}

Most engineering faculty are accustomed to teaching students with strong backgrounds in mathematics and science, and often with knowledge from lower-level engineering courses. 
Therefore, engineering faculty often teach courses with the idea that students can perform complex mathematical operations and are able to derive out the equations to be applied to different situations. However, the students in this course, despite being well-accomplished academically, did not necessarily have knowledge of Calculus, differential equations, or collegelevel Physics or Chemistry. Therefore, it would not have been successful to teach a course involving the derivation and use of engineering equations, or with the expectation that students were familiar with even simple Physics and Chemistry concepts.

The approach taken in this course was to use a small number of equations, and to keep those equations as simple as possible. The equations were used to help students visualize what was being discussed, and were at a level where only algebra was necessary for understanding and solving the equations. Even though some students would have had Calculus, integrals and derivatives were avoided as not all students in the course were familiar with these topics. Furthermore, the science concepts employed were explained from basic principles, which were related to what students experienced in everyday life when possible. The level of the science material was placed at what would be expected from a good high school student upon graduation from high school. As these were students in the Honors College, they typically picked up the concepts quickly with this approach, but were appreciative of not having been expected to remember topics that they might have learned several years earlier but never used since then.

\section{Quantitative vs. Qualitative Descriptions}

It is a challenge in this type of course to know when to rely on quantitative or qualitative descriptions of phenomena. This ties closely with the first challenge of the level at which to teach the material. Engineering faculty have traditionally relied a great deal on quantitative descriptions or solutions to problems, sometimes at the loss of a tactile sense of what is physically occurring on the part of the students. (For example, a class might calculate that an air compressor uses $20 \mathrm{~kW}$ of power, but students may be left to wonder what can be done with the amount of compressed air that is produced.) As many of the students in this course would have had little practical exposure to quantitative measures involving energy, it was opted to rely more on qualitative discussion of equipment, processes, and phenomena and less on quantitative calculations of what might be expected from some process. However, simple quantitative calculations were performed to illustrate some of the qualitative descriptions in a more concrete means. For example, after discussing how much energy will be saved by replacing one incandescent light bulb with an LED bulb, one can then easily calculate how this can build into large energy savings over a house, or city, and then this savings can be related to how many power plants may be unneeded after such a change. The described concept was done qualitatively, but then calculations were introduced to determine just how large of a change might be possible.

\section{Course Grading}

As this course did not use numerical grading of tests consisting of calculation or short answer problems, as used in most engineering courses, the instructor had to determine a means of assessing student performance as one would expect in a seminar course. A seminar course should involve student participation in discussions. To assure that students contributed 
something to the course discussions, students were expected to lead one discussion during the semester, and write a summary of that discussion. This provided one component of the portion of the grade based on class participation. Furthermore, the instructor monitored the class discussions, and kept track on the approximate amount and quality of participation by the students. The instructor then translated these factors into a letter grade representing the class participation.

As the majority of the grade was based on written papers, a method for grading the papers needed to be developed. The instructor chose to assign a letter grade to each paper, and then convert these letter grades over to a 4-point scale, and apply this scale to the weighting for each paper to develop a letter grade for the course. In retrospect, this was probably not the best system to be used. The instructor would recommend that faculty teaching this type of course develop a numerical scale based on specific rubrics to grade the papers. This would still involve some subjectivity on the part of the instructor, but such a scale would make the determination of a more finely-scaled grade to be determined, and would more closely match the types of grading often used in engineering courses. Such a rubric scale could also be applied to the class participation grade. This would move the course grading more towards a rigorous numerical method than had been employed in this class.

\section{Preparing for the Seminar Format}

Most engineering courses are not taught in a seminar format, and so most faculty are not particularly prepared for such a format. Yet, a seminar format in which a small number of students engage in open discussion on the topics of the course can be very rewarding for both students and faculty. There are several key aspects of a seminar format that the faculty member must be prepared for in order for the format to be successful.

Students must be engaged: To be successful, a large majority of the students (and preferably all of the students) must be participating in the discussion. If only a few students participate, then the discussion can quickly degenerate into a situation where most of the students just observe the others who are participating, and a lack of dialogue on a diversity of ideas ensues. For the nonparticipants, the discussion can be viewed as a passive lecture, and the discussion does not challenge these students. The instructor needs to draw all students into the discussion. This may involve actively calling on students who are not participating to hear their opinions. In addition, in this course, the students were forced to be engaged at least in the class discussion in which they led the discussion. The instructor also, at the beginning of a class session, did not discourage wide-ranging discussions on topics that may or may not have been related to the course topic - such discussions served as a way to make the students more comfortable with each other by expressing their thoughts on topics with which they were more comfortable.

Encourage advanced preparation: Students who know in advance what the topic of the discussion will be are more likely to (a) be prepared to discuss the topic, and (b) engage in the discussion. Presenting a question for the class to discuss without advanced warning can work if the question is a natural extension of what the class has been discussing. But if the question likely requires some background research by the students, it should be given to the students in the previous class. 
Do not allow one or two students to dominate the discussion: Even if all students participate in a discussion, there is the risk that a few students may make the majority of the comments. This limits what others may get out of the seminar, and also limits the variety of viewpoints heard.

Be prepared to intercede: If a discussion is drifting off-topic, or if students are making inappropriate comments or bullying others, or if students appear to be confused over the material, the instructor should be prepared to intercede. It is important for all students to feel comfortable in the seminar, and they should not feel intimidated into not voicing their opinions. In addition, if the discussion has moved away from the intended topic to one that is irrelevant (as the discussion could move in the direction of another relevant topic), the instructor should move the class back on track by asking questions to refocus the discussion. Also, if the students are presenting incorrect information as "facts", it is appropriate for the instructor to question them on these if no one else in the class is doing so.

Overall, the instructor should act as a facilitator/moderator of the seminar, even if he or she is not actually leading the discussion. It is the responsibility of the instructor to ensure that the seminar is beneficial to the students in the class, and that the material in the class is being adequately covered. While this may be more difficult in a seminar format than in a lecture or laboratory format, instructors can quickly learn how to teach effectively in a seminar format.

\section{Flexibility}

While instructors tend to want to think that their course is the most important course that a student is taking at that time, the reality is that this type of course - a science or engineering course for non-STEM majors - may not be the top priority of the students in the course. To allow the students to complete their discipline-specific courses adequately, and to still get the most out of this type of course, the instructor should consider being very flexible in how the course requirements are met. For example, in this course, the instructor gave target dates for when the short papers and final paper should be submitted, but did not penalize students for submitting the papers after the target dates. This allowed students to prioritize their work and budget their time as necessary for their particular course schedule, but also gave students "deadlines" to stay on track in this course. The instructor found that in this class, the vast majority of students turned in their papers within a few days of the target date, and only two students seriously abused this flexibility by delaying turning in their papers until near (or after) the end of the semester. Furthermore, the instructor allowed the students to volunteer for the date that they would lead the class discussion, again providing the students with flexibility in meeting the course requirements in conjunction with the requirements of their other courses.

Another way in which flexibility was used was by encouraging students to explore topics of their particular interest for their short and final papers. Only one topic was required of all students. This allowed students to tailor their learning to energy issues that were of the most interest to them, and it allowed some of the students to connect this course material to their own major. 


\section{Benefits to the Instructor}

Teaching this type of course can offer instructors benefits that can extend to the more typical engineering courses that they routinely teach. Some of the benefits that the instructor of this course identified are listed below.

\section{Carryover of the teaching style to larger lecture courses}

As discussed above, teaching a seminar course involves a different style of teaching than one may often use in a large lecture course. Many instructors who have taught both large and small lecture courses may have already identified differences between such courses. A seminar course should be designed around class discussions. So the instructor needs to be able to draw more students into the discussion. Developing methods of increasing class participation can be then used in larger lecture classes so as to keep the students in an active-learning mode.

\section{Different methods of explaining the material}

As mentioned, when teaching a seminar course on an engineering topic to a class of non-STEM majors, one must find methods of teaching material that differ from what is often used in engineering lectures. In teaching this course, the instructor relied on a descriptive approach using few equations. In many engineering lectures, the instructor might briefly explain a topic descriptively, but then will often move into equation development and the application of those equations in example problems. In such a situation, students may not get an understanding of what is actually physically occurring in practice. Bringing in the type of descriptive approach used in this seminar class allows the instructor to help explain the material on a more fundamental level than done in many engineering lectures, which should help the students understand the material at a deeper level than may be realized through seeing equations. From an instructor's viewpoint, this approach also reminds him or her to bring more of their experiences into the lecture, which often makes the lecture more enjoyable for both the instructor and the students.

\section{Developing communication methods for non-engineering audiences}

If engineering faculty are to reach out to more non-technical audiences to improve technical literacy in the United States, they need to have practice in communicating the information to such audiences. Refining one's delivery style through this type of seminar course for non-STEM majors provides a platform for developing the skills necessary for communicating technical information to non-technical audiences. Therefore, teaching this type of class can better prepare engineering faculty to inform a wider audience about their work.

\section{Appreciation of non-engineering majors}

When one in engaged with only students from one particular discipline, one can tend to forget or ignore the abilities and contributions from students in other disciplines. By teaching classes to non-engineering students, an engineering instructor can gain an appreciation for the abilities of 
these non-engineering students. In teaching this engineering course to non-engineering students in the Honors College, the author was able to identify students who were using forms of the design process, and recognizing their perspectives on analyzing information. Recognizing these traits in non-engineering students allows an engineering faculty member to see opportunities for more ways to reach out to such students and improve technological literacy across disciplines. In addition, teaching this type of course opens up the possibility for collaborative activities with disciplines that might not have been considered previously by the faculty member.

\section{Future Plans}

The author plans to teach this course again. There are initial discussions about increasing the role of the Honors College in the College of Engineering and Applied Science (CEAS) at UWM in the future, and this course could be part of those expanded plans. If the plans do not materialize, the author does plan to approach the Honors College with the offer to teach the course again. In such an offering, the author plans to gain a better quantitative understanding of how this course impacted the technological and engineering literacy of the students through pre/post surveys and quizzes. Methods for accomplishing this and a discussion of the importance of such evaluation can be found elsewhere. ${ }^{12}$ The author also plans to work with other faculty in CEAS to help them develop courses on other technological topics that would be of wide interest to Honors College students who are not engineering majors.

\section{Summary}

In this paper, the experiences had by a long-time engineering faculty member while teaching a seminar course on energy to non-STEM majors in the Honors College at UWM were described. Some of the challenges faced by the instructor were presented, along with suggestions on how these challenges can be overcome by others considering teaching such a course. In addition, some of the benefits recognized by the instructor in teaching such a class were described.

While potentially moving many engineering faculty out of their comfort zones, teaching small seminar-based classes on engineering topics to non-STEM majors can be very rewarding for engineering faculty, and offer an opportunity to improve the technical literacy of students in nontechnical disciplines.

\section{Acknowledgements:}

The author would like to thank the Mechanical Engineering Department in CEAS at UWM for allowing him the opportunity to teach a course outside of the department, and the Honors College at UWM, under the direction of Dr. Peter Sands and Ms. Robin Ruback for suggesting that he teach the course described.

\section{References:}

1. J. Krupczak, J.W. Blake, K.A. Disney, C.O. Hilgarth, R. Libros, M. Mina, and S.R. Walk, "Defining Engineering and Technological Literacy," 2012 ASEE Annual Conference, Paper No. AC 2012-5100. San Antonio, TX. (2012) 
2. AAAS. Project 2061: Benchmarks for Science Literacy, American Association for the Advancement of Science, Oxford University Press. (1993)

3. NAE. Changing the Conversation: Messages for Improving the Public Understanding of Engineering. Committee on Public Understanding of Engineering Messages. National Academy of Engineering. Washington, D.C., National Academies Press. (2008)

4. D. Klein, and R. Balmer, "Liberal Arts and Technological Literacy," 2006 ASEE Annual Conference, Paper No. 2006-912, Chicago, IL. (2006)

5. International Technology Education Association, Standards for Technological Literacy: Content for the Study of Technology, $3^{\text {rd }} \mathrm{Ed}$.

https://www.iteea.org/File.aspx?id=67767\&v=b26b7852 Accessed: December 2016. (2007)

6. G. Pearson and A.T. Young (eds.) Technically Speaking: Why All Americans Need to Know More about Technology, Committee on Technological Literacy. National Academy of Engineering. Washington, D.C., National Academics Press (2002).

7. W.R. Loendorf, "Using Stories to Promote Technological Literacy," 2012 ASEE Annual Conference, Paper No. 2012-3893, San Antonio, TX. (2012)

8. D. Ollis, and J. Krupczak, "Teaching Technological Literacy: An Opportunity for Design Faculty," 2012 ASEE Annual Conference, Paper No. 2006-620, Chicago, IL. (2006)

9. J. Blake, "Using Movies to Explore Elements of Technological Literacy," 2009 ASEE Annual Conference, Paper No. 2009-1691, Austin, TX. (2009)

10. U.S. Department of Energy, https://energy.gov/eere/amo/industrial-assessment-centers-iacs Accessed: January 2017 (2017).

11. Princeton Environmental Institute, http://cmi.princeton.edu/wedges/ Accessed: January 2017 (2017).

12. E. Gamire and G. Pearson (eds). Tech Tally: Approaches to Assessing Technological Literacy, Committee on Assessing Technological Literacy. National Academy of Engineering, Washington, D.C., National Academics Press (2006). 